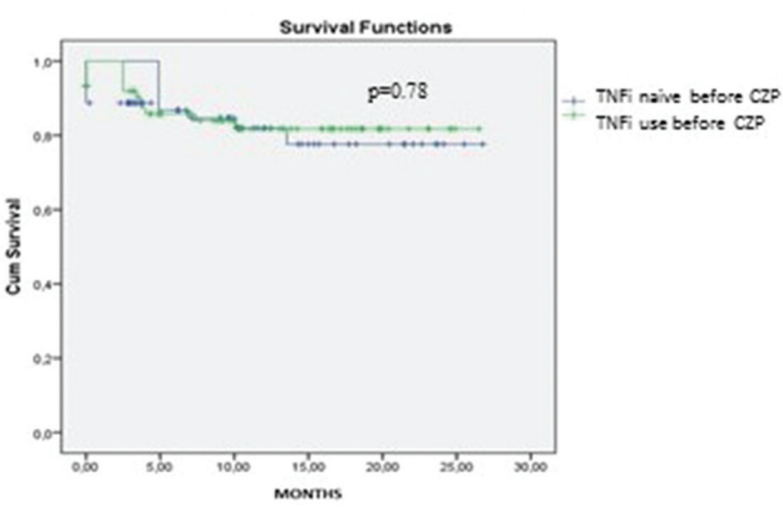

Abstract SAT0274 - Figure 1. CZP survival in AS and nrAxSpA patients

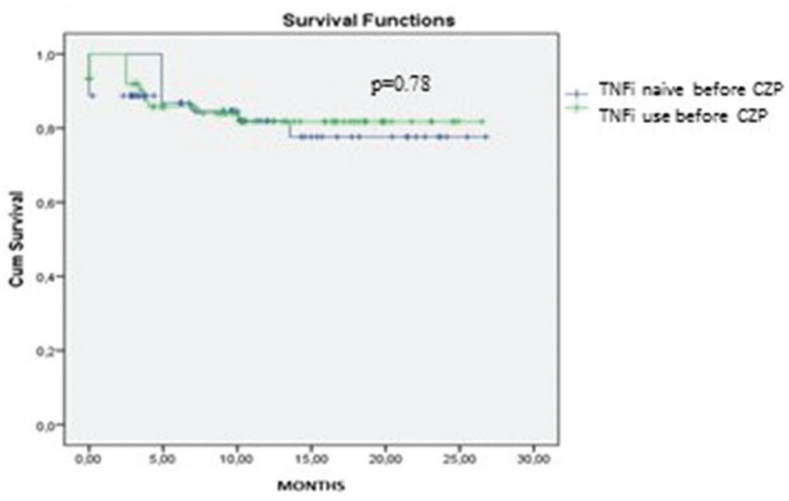

Abstract SAT0274 - Figure 2. CZP survival in patients with and without history of TNFi use before CZP

Conclusions: In this single centre biological SpA cohort, adherence to CZP therapy seems to be high with a first year survival rate of $83 \%$ and there was no difference between AS and nrAxSpA patients.

Disclosure of Interest: None declared

DOI: 10.1136/annrheumdis-2018-eular.4649

\section{SAT0275 VITAMIN D INSUFFICIENCY IS ASSOCIATED WITH VERTEBRAL FRACTURES IN PATIENTS WITH AXIAL SPONDYLOARTHRITIS}

C. Romera-Lopez ${ }^{1}$, C. Fernández-Carballido ${ }^{2}$, M.P. Martínez-Vidal ${ }^{3}$, T. Pedraz ${ }^{2}$. ${ }^{1}$ Reumatología, Hospital Vinalopo, Elche, Alicante; ${ }^{2}$ Reumatología, Hospital General Universitario de Elda, Elda, Alicante; ${ }^{3}$ Reumatología, Hospital General Universitario de Alicante, Alicante, Spain

Background: Vitamin D insufficiency is common in general population, and it has been associated with the development and activity of several diseases, such as cardiovascular and autoinmune diseases. In patients with axial spondyloarthritis (axSpA) vitamin $\mathrm{D}(25(\mathrm{OH}) \mathrm{D})$ insufficiency has been associated with disease activity, but studies in these patients that associate $25(\mathrm{ODH}) \mathrm{D}$ insufficiency with vertebral fractures (VF) are scarce.

Objectives: To evaluate the associations between 25(OH)D levels and VF, as well as the 10 year-estimated risk (FRAX) and low bone mineral density (BMD), in patients with axSpA.

Methods: Cross-sectional study of patients with axSpA (ASAS criteria); 25(ODH) $D$ insufficiency when $<30 \mathrm{ng} / \mathrm{mL}$ and BMD measured by Lumbar spine (LS) and femoral neck (FN) Dual X-ray absorptiometry (DXA). Evaluation of VF with semiquantitative method (Genant) in thoracolumbar X-rays. Bivariate and multivariate analyses performed, and $p$ values $<0.05$ considered significant.

Results: We included 206 axSpA patients (70\% male; 86\% AS714\% nr-axSpA); age $52 \pm 14$ and disease duration $12.9 \pm 10.3$ years; ASDAS-CRP $2.2 \pm 0.9$, ASDAS-ESR $2.5 \pm 0.9$; total mSASSS $20.5 \pm 19.1$ and $25(\mathrm{OH}) \mathrm{D}$ levels 19.8 $\pm 9.3 \mathrm{ng} / \mathrm{mL}$ (all values are mean $\pm \mathrm{SD}$ ); with $85.7 \%$ of the patients having insufficiency; VF were observed in $34 \%$ of the patients. The prevalence of low BMD was higher in FN $45.2 \%$ (z-score) and 28.9\% (t-score) than in LS 25.7\% (z-score) and $29.9 \%$ (t-score).
These differences were even higher when 25(OH)D insufficiency was also present (table)

In multivariate analysis, $25(\mathrm{OH}) \mathrm{D}$ was associated with FN BMD ( $\mathrm{p}=0.001)$; without association with LS BMD. Vitamin $\mathrm{D}$ insufficiency was directly associated with the presence of $\mathrm{VF}$ [OR $0.95(95 \% \mathrm{Cl} 0.86-0.98) ; \mathrm{p}=0.029$ ] and a higher 10 year-estimated risk of fracture (major FRAX [OR $0.92(95 \% \mathrm{Cl} 0.81-0.96) ;(\mathrm{p}=0.036)]$.

\begin{tabular}{|c|c|c|c|}
\hline \multicolumn{4}{|c|}{ Differences between axSpA patients with/without 25(OH)D insufficiency } \\
\hline & Insufficiency & No insufficiency & $p$ value \\
\hline Patients (\%) & $85.7 \%$ & $14.3 \%$ & \\
\hline Vertebral fractures (\%) & $38.7 \%$ & $32.48 \%$ & $\mathrm{p}=0.049$ \\
\hline FRAX major & $8.7 \pm 6.7$ & $7.5 \pm 6.4$ & $\mathrm{p}=0.036$ \\
\hline BASDAI & $4.2 \pm 2.2$ & $3.1 \pm 1.3$ & $p=0.003$ \\
\hline BASFI & $3.8 \pm 2.5$ & $3.0 \pm 2.4$ & $p=0.000$ \\
\hline ASDAS-CRP & $2.21 \pm 0.15$ & $1.89 \pm 0.16$ & $\mathrm{p}=0.003$ \\
\hline ASDAS-ESR & $2.72 \pm 0.21$ & $2.19 \pm 0.25$ & $\mathrm{p}=0.002$ \\
\hline Low FN BMD (\%) & $56.4 \%$ & $44.6 \%$ & $p=0.014$ \\
\hline FN t-score & $0.80 \pm 0.31$ & $0.92 \pm 0.44$ & $\mathrm{p}=0.002$ \\
\hline FN z-score & $0.84 \pm 0.28$ & $0.9 \pm 0.31$ & $\mathrm{p}=0.002$ \\
\hline
\end{tabular}

Values are mean \pm standard deviation (SD) unless otherwise specified.

Conclusions: In patients with axSpA, vitamin $\mathrm{D}$ insufficiency is even more generalised than in general population. Low $25(\mathrm{OH}) \mathrm{D}$ is associated with lower FN BMD and more vertebral fractures, as well as increased disease activity and disability. Vertebral fractures are a serious complication of axSpA, so $25(\mathrm{OH}) \mathrm{D}$ insufficiency should be taken into account in the management of the comorbidities of the patients with axial spondyloarthritis.

\section{REFERENCES :}

[1] Cai G, et al. Clin Chim Acta 2015 Jan 1;438:316-22.

[2] Carmona L, et al. grupo ESPOGUIA. Reumatol Clin 2010 Mar;6(Supp 1);1-5.

[3] Davey-Ranasinghe N, et al. Curr Opini Rheumatol 2013 Jul;25(4):509-16.

Disclosure of Interest: None declared

DOI: 10.1136/annrheumdis-2018-eular.2477

\section{SAT0276 UVEITIS DURING ANTI-TNF THERAPY IN PATIENTS WITH AXIAL SPONDYLOARTHRITIS: A PARADOXICAL} EVENT OR DISEASE MANIFESTATION?

C. Ancuta ${ }^{1,2}$, C. Pomirleanu ${ }^{2,3}$, R. Paiu ${ }^{1}$, G. Strugariu ${ }^{1}$, L. Petrariu ${ }^{1}$, C. Bran ${ }^{4}$ E. Ancuta ${ }^{5}$, R. Chirieac ${ }^{6} .{ }^{1}$ Clinical Rehabilitation Hospital; ${ }^{2}$ University of Medicine and Pharmacy Grigore T Popa Iasi; ${ }^{3}$ Clinica Rehabilitation Hospital, lasi; ${ }^{4}$ Sfantu Ioan Emergency Hospital, Suceava; ${ }^{5}$ Elene Doamna Clinical Hospital;

${ }^{6}$ SANOCARE Medical and Research Center, lasi, Romania

Background: Although widely recognised as extra-articular manifestations of axial spondyloarthritis $(\operatorname{axSpA})$, uveitis developing throughout anti-TNF $\alpha$ treatment is difficult to be classified as disease related or paradoxical event.

Objectives: We aimed to evaluate the incidence of new onset or relapsing uveitis in patients with axSpA receiving TNF inhibitors.

Methods: We performed a cross-sectional retrospective study evaluating 126 consecutive active axSpA exposed to TNF $\alpha$ inhibitors according to the local recommendations, followed-up in a single rheumatology department. Patients identified with uveitis were systematically assessed based on a predefined protoco comprising (i) data about uveitis (de novo or flare; unique episode or recurrence; acute or chronic; anterior, posterior, intermediary or panuveitis; uni or bilateral; outcomes), (ii) responsible medication (drug exposure prior to uveitis, biologicnaïve or experimented axSpA, continuation or switching to another biologic) and (iii) rheumatic condition (activity, response to treatment, extra-articular manifestations, disease duration).

Results: 91 biologic naïve axSpA and 35 receiving more than one anti-TNF $\alpha$ were recruited; among them, 318 patient-years exposed to etanercept, 225.37 patient-years to adalimumab, 113.52 patient-years to infliximab, 30.49 patientyears on golimumab. A history of uveitis was found in $27.77 \%$ ( 35 cases).

We reported 12 patients developing at least one episode of uveitis during biologic treatment (7 de novo, 10 recurrent uveitis); etanercept was mostly associated with uveitis (8 episodes, 2.51 per 100 patient-years), but also monoclonal antibodies, 3 with golimumab (9.83 per 100 patien-years), 2 under infliximab (1.76 per 100 patien-years), surprisingly, 3 with adalimumab ( 1.33 per 100 patien-years). Only 3 axSpA had uveitis before starting anti-TNFs.

Uveitis was described irrespective of the prior exposure to biologics, mainly in bioexperimented patients, ${ }^{9}$ aged between 26 and 72 , with disease duration of 6 to 38 years, occurring any-time during biologics (2-116 months). Acute anterior uveitis was commonly reported, only one case of complicated panuveitis.

3 cases (one infliximab, two golimumab) had benefit with switching to another TNF blocker, but in most reported cases uveitis was solved without anti-TNFo 